\title{
PREFERENSI PILIHAN JENIS HUNIAN BERDASARKAN PERILAKU BELANJA GENERASI Z
}

\author{
Viola Malta Ramadhani \\ Dosen Prodi S1 Pendidikan Teknik Bangunan, Jurusan Teknik Sipil, Fak. Teknik, \\ Universitas Negeri Malang \\ e-mail: viola.ramadhani.ft@um.ac.id \\ Muhammad Faqih \\ Dosen Jurusan Arsitektur, Fakultas Arsitektur Desain dan Perencanaan, \\ Institut Teknologi Sepuluh Nopember \\ e-mail: faqih@arch.its.ac.id \\ Purwanita Setijanti \\ Dosen Jurusan Arsitektur, Fakultas Arsitektur Desain dan Perencanaan, \\ Institut Teknologi Sepuluh Nopember \\ e-mail: psetijanti@arch.its.ac.id
}

\begin{abstract}
ABSTRAK
Abstrak Generasi z merupakan bagian dari generasi milenial. Meski demikian, karakteristik perilaku dan kepribadian generasi z berbeda dengan generasi sebelumnya. Tujuan dari penelitian ini yakni untuk mengetahui preferensi pilihan jenis hunian berdasarkan perilaku belanja generasi z. Penelitian ini merupakan penelitian kualitatif deskriptif. Hasil penelitian menyatakan bahwa meski generasi y dan z termasuk generasi milenial, namun ada beberapa karakteristik umum yang berbeda diantara keduanya dalam memilih hunian. Hal ini dibuktikan melalui preferensi pilihan hunian generasi $z$ yang menjadi responden dalam penelitian ini berdasarkan perilaku belanjanya, meliputi aspek cara mencari produk hunian, merek pengembang, kepemilikan hunian, jenis properti hunian, dan privasi.
\end{abstract}

\section{Kata kunci : Generasi Z, Jenis Hunian, Perilaku Belanja, Preferensi Konsumen}

\begin{abstract}
$Z$ generation is part of the millennial generation. However, $z$ generation has different behavior and personality characteristics from the previous generation. The purpose of this study is to determine the choice of residential type preferences based on the consumer behavior of $z$ generation. This research is a descriptive qualitative research. The results of this study indicate that although y generations and $z$ generation belong to the millennial generation, there are some general characteristics that are different between the two in choosing residential. This is evidenced by the preference of $z$ generation residential types who became respondents in this study based on their consumer behavior including aspects of finding
\end{abstract}

PAWON: Jurnal Arsitektur, Nomor 02 Volume V, Juli-Desember Tahun 2021, ISSN 2597-7636 
the residential product, prestigious developer brand, residential ownership, type of residential property, and privacy.

\section{Keywords : Z Generation, Residential Type, Consumer Behavior, Consumer Preference}

\section{PENDAHULUAN}

Manusia cenderung memilih hunian berdasarkan tujuan dan nilai umum yang dikejar. Ballantyne (2001) dalam buku "What is Architecture" mengatakan bahwa arsitektur relatif kompleks dengan banyak bidang yang terlibat didalamnya. Hal ini tampak salah satunya dari histori pendefinisian hunian dari masa ke masa, mulai dari gaya, bentuk, penataan ruang, ukuran, material, sampai tujuan dan preferensi kepemilikan mereka terhadap hunian.

Hunian merupakan salah satu kebutuhan dasar manusia dan kebutuhan di tingkat terendah (Globe, 1987). Dalam menentukan hunian, ada banyak sekali aspek yang diperhatikan konsumen berdasarkan keinginan dan kebutuhannya. Setiap konsumen memiliki preferensi masingmasing dalam memilih huniannya. 'Common sense' tiap generasi berdampak pula pada preferensi umum mereka terhadap hunian (Jansen, 2011). 'Common sense' adalah kebiasaan akibat dilakukan secara terus menerus hingga mengakar dalam diri seseorang.

Dalam studi mengenai environmental behavior, kumpulan individu dapat memiliki kesamaan karakteristik jika berada pada generasi yang sama (Rapoport, 2005). Generasi z sebagai bagian dari generasi milenial tentunya mempunyai kepribadian dan karakteristik perilaku yang berbeda dari generasi sebelumnya, bahkan dengan generasi y yang juga merupakan bagian generasi milenial. Salah satunya yaitu dari karakter perilaku belanja generasi z

Dalam 5 sampai 10 tahun mendatang, generasi z akan menjadi future market properti hunian yang potensial sebagai pembeli rumah pertama untuk mereka huni atau sekedar berinvestasi. Oleh karena itu, perlu dilakukan sebuah studi guna mengetahui preferensi pilihan jenis hunian yang sesuai dengan karakteristik generasi $z$ berdasarkan perilaku belanjanya sebab belum ada yang secara khusus membahas hal tersebut. Dengan mengetahuinya, maka dapat mempermudah produsen hunian/ developer perumahan untuk menyediakan produk hunian yang dapat diserap pasar. Ekananda (2019) mengatakan bahwa guna menghindari kegagalan proyek, maka developer perumahan harus memperbarui diri secara teratur dengan kebutuhan konsumen. Salah satu caranya dengan mengetahui preferensi konsumen. 


\section{TINJAUAN PUSTAKA}

Penelitian ini merupakan penelitian tentang environmental behavior dan bidang arsitektur. Di bidang arsitektur, penelitian ini terkait dengan real estate. Pengertian dari real estate yaitu hal-hal yang tidak bergerak, seperti bangunan yang melekat secara permanen pada tanah (Brueggeman, Fisher, 2001). Hunian termasuk dalam kategori residensial yang dibagi menjadi single family homes dan multi family residence. Single family homes contohnya yakni rumah tunggal/ rumah tapak. Sedangkan contoh multi family residence meliputi apartemen, kondominium, rusun, dan lain sebagainya. (Andersen, 2006)

Menurut teori Hierarchy of Needs yang dikemukakan oleh Maslow, memiliki hunian pertama menjadi salah satu kebutuhan dasar manusia yang selanjutnya dapat berkembang menjadi kebutuhan lanjutan (Globe, 1987). Oleh karena itu, dalam memilih dan membeli hunian tentu terdapat banyak aspek yang menjadi pertimbangan konsumen. Tiap konsumen memiliki preferensinya masing-masing. Menurut Kotler (1997), pengertian dari preferensi konsumen ialah pilihan antara 'suka' atau 'tidak' terhadap suatu produk (barang atau jasa). Preferensi konsumen dapat diamati dari 4 aspek Teori Bauran Pemasaran yang dikemukakan oleh Kotler, yaitu Price (Harga), Place (Tempat), Product (Produk), serta Promotion (Promosi). Preferensi bersifat swatantra terhadap harga dan pendapatan. Hal ini kemudian dapat mempengaruhi konsumen dalam memutuskan suatu pembelian (Sunyoto, 2006).

Adapun yang dimaksud sebagai konsumen dalam penelitian ini adalah generasi $z$ yang termasuk dalam generasi milenial. Berikut ini merupakan tabel mengenai perbedaan karakteristik generasi $z$ dengan generasi lainnya:

Tabel 1.

Karakteristik Umum Antar Generasi

\begin{tabular}{|c|c|c|c|c|c|}
\hline Keterangan & $\begin{array}{c}\text { Traditionalist } \\
\text { Generation }\end{array}$ & $\begin{array}{l}\text { Baby } \\
\text { Boomer }\end{array}$ & Generasi X & Generasi Y & Generasi Z \\
\hline & $\begin{array}{l}\text { Veteran, Silent } \\
\text { Generation }\end{array}$ & $\begin{array}{l}\text { "Me" } \\
\text { generation }\end{array}$ & Post Boomers & $\begin{array}{l}\text { Milenials, } \\
\text { Echo } \\
\text { Boomers }\end{array}$ & $\begin{array}{l}\text { Generation, } \\
\text { centennials, } \\
\text { founders }\end{array}$ \\
\hline Lahir tahun & $1900-1945$ & 1946-1964 & $1965-1976$ & 1977-1995 & $\begin{array}{l}\text { 1996- } \\
\text { sekarang }\end{array}$ \\
\hline Terpengaruh & $\begin{array}{l}\text { Perang Dunia } \\
\text { II, Perang } \\
\text { Korea, Depresi } \\
\text { Besar }\end{array}$ & $\begin{array}{l}\text { Civil right, } \\
\text { Perang } \\
\text { Vietnam, } \\
\text { Cold War }\end{array}$ & $\begin{array}{l}\text { Krisis energi, } \\
\text { akhir dari Cold } \\
\text { War }\end{array}$ & $\begin{array}{l}\text { Media } \\
\text { digital, } \\
\text { serangan } \\
\text { teroris }\end{array}$ & $\begin{array}{l}\text { Teknologi, } \\
\text { internet \& } \\
\text { media } \\
\text { sosial, resesi } \\
\text { ekonomi } \\
\text { besar, WTC } \\
\text { 9/11 }\end{array}$ \\
\hline
\end{tabular}

PAWON: Jurnal Arsitektur, Nomor 02 Volume V, Juli-Desember Tahun 2021, ISSN 2597-7636 


\begin{tabular}{|c|c|c|c|c|c|}
\hline Keterangan & $\begin{array}{c}\text { Traditionalist } \\
\text { Generation }\end{array}$ & $\begin{array}{c}\text { Baby } \\
\text { Boomer }\end{array}$ & Generasi X & Generasi Y & Generasi Z \\
\hline Sifat & $\begin{array}{l}\text { Disiplin, } \\
\text { berdedikasi, } \\
\text { patriotism } \\
\text { tinggi, kerja } \\
\text { keras, } \\
\text { tanggung } \\
\text { jawab }\end{array}$ & $\begin{array}{l}\text { Anti perang, } \\
\text { anti } \\
\text { pemerintah, } \\
\text { mau } \\
\text { membuat } \\
\text { perubahan }\end{array}$ & $\begin{array}{l}\text { Mengutama- } \\
\text { kan keseimba- } \\
\text { ngan,mengu- } \\
\text { tamakan } \\
\text { perbedaan, } \\
\text { pendidikan } \\
\text { tinggi }\end{array}$ & $\begin{array}{l}\text { Berprestasi, } \\
\text { percaya diri, } \\
\text { toleransi } \\
\text { tinggi, street } \\
\text { smart }\end{array}$ & $\begin{array}{l}\text { Bergantung } \\
\text { pada } \\
\text { teknologi, } \\
\text { menerima } \\
\text { perbedaan, } \\
\text { ingin punya } \\
\text { banyak } \\
\text { pengalaman }\end{array}$ \\
\hline Menghargai & $\begin{array}{l}\text { Keluarga, } \\
\text { komunitas }\end{array}$ & Kesuksesan & Waktu & Individualitas & Keragaman \\
\hline Urusan uang & $\begin{array}{l}\text { Belanja } \\
\text { menggunakan } \\
\text { tunai, } \\
\text { menabung }\end{array}$ & $\begin{array}{l}\text { Beli } \\
\text { sekarang, } \\
\text { bayar } \\
\text { belakangan }\end{array}$ & $\begin{array}{l}\text { Konservatif, } \\
\text { menabung }\end{array}$ & $\begin{array}{l}\text { Mendapat- } \\
\text { kan uang } \\
\text { untuk } \\
\text { dihabiskan }\end{array}$ & $\begin{array}{l}\text { Mendapatka } \\
\text { n uang untuk } \\
\text { dihabiskan }\end{array}$ \\
\hline Etos kerja & $\begin{array}{l}\text { Berdedikasi, } \\
\text { pekerja keras, } \\
\text { mengedepan- } \\
\text { kan } \\
\text { perusahaan }\end{array}$ & $\begin{array}{l}\text { Sangat rajin, } \\
\text { bekerja } \\
\text { keras demi } \\
\text { identitas, } \\
\text { mementingk } \\
\text { an kualitas }\end{array}$ & $\begin{array}{l}\text { Bekerja lebih } \\
\text { pintar bukan } \\
\text { lebih kama, } \\
\text { skeptis, } \\
\text { bergantung } \\
\text { pada diri } \\
\text { sendiri }\end{array}$ & $\begin{array}{l}\text { Ambisius, } \\
\text { multitasking, } \\
\text { kewirausa- } \\
\text { haan tinggi, } \\
\text { gigih }\end{array}$ & $\begin{array}{l}\text { Hobi } \\
\text { menjadi } \\
\text { pekerjaan, } \\
\text { kewirausa- } \\
\text { haan tinggi, } \\
\text { mementing- } \\
\text { kan kualitas }\end{array}$ \\
\hline
\end{tabular}

Sumber: Ramadhani (2018)

Saat ini, generasi milenial merupakan future market atau konsumen masa depan (Kasali, 2011). Oleh karena itu, dalam melakukan penelitian ini perlu juga untuk mengetahui karakter perilaku belanja generasi z sebagai segmentasi pasar yang dituju. Melalui segmentasi pasar, akan terjadi pengelompokan konsumen secara homogen berdasarkan suatu kriteria (Sudarman, 2004). Hal tersebut akan mempermudah produsen untuk mengetahui preferensi konsumennya guna menghasilkan produk yang sesuai dengan keinginan serta kebutuhan pasar, dalam hal ini adalah generasi $z$.

Tabel 2.

Perilaku Belanja Antar Generasi

\begin{tabular}{|c|c|c|c|}
\hline KETERANGAN & GENERASI X & GENERASI Y & GENERASI Z \\
\hline $\begin{array}{l}\text { Mencari Barang } \\
\text { atau Produk atau } \\
\text { Jasa yang Ingin } \\
\text { Dibeli }\end{array}$ & $\begin{array}{l}\text { Memanfaatkan } \\
\text { smartphone/gadget } \\
\text { untuk sekadar } \\
\text { mencari info. } \\
\text { Transaksi } \\
\text { dilakukan offline } \\
\text { atau secara } \\
\text { langsung }\end{array}$ & $\begin{array}{l}\text { Memanfaatkan } \\
\text { smartphone untuk } \\
\text { mencari info dan } \\
\text { bertransaksi }\end{array}$ & $\begin{array}{l}\text { Memanfaatkan } \\
\text { smartphone untuk } \\
\text { mencari info dan } \\
\text { bertransaksi }\end{array}$ \\
\hline
\end{tabular}

PAWON: Jurnal Arsitektur, Nomor 02 Volume V, Juli-Desember Tahun 2021, ISSN 2597-7636 


\begin{tabular}{|c|c|c|c|}
\hline KETERANGAN & GENERASI $\mathbf{X}$ & GENERASI Y & GENERASI Z \\
\hline $\begin{array}{l}\text { Media Sosial atau } \\
\text { Mesin Pencari }\end{array}$ & $\begin{array}{l}\text { Lebih banyak } \\
\text { menggunakan } \\
\text { mesin pencari } \\
\text { seperti google, } \\
\text { dibandingkan } \\
\text { media sosial }\end{array}$ & $\begin{array}{l}\text { Lebih menyukai } \\
\text { media sosial } \\
\text { dibandingkan mesin } \\
\text { pencari }\end{array}$ & $\begin{array}{l}\text { Media sosial lebih } \\
\text { disukai } \\
\text { dibandingkan } \\
\text { mesin pencari }\end{array}$ \\
\hline Motivasi Belanja & $\begin{array}{l}\text { Harga mahal bukan } \\
\text { menjadi masalah } \\
\text { asalkan produk } \\
\text { berkualitas. Tren } \\
\text { bukan sesuatu } \\
\text { yang harus } \\
\text { dipedulikan dalam } \\
\text { memilih produk. }\end{array}$ & $\begin{array}{l}\text { Motivasi belanja } \\
\text { timbul karena } \\
\text { teman-teman atau } \\
\text { komunitasnya } \\
\text { memakai } \\
\text { barang/produk } \\
\text { tersebut. Generasi y } \\
\text { mencari barang } \\
\text { yang harganya } \\
\text { paling terjangkau. }\end{array}$ & $\begin{array}{l}\text { Produk yang } \\
\text { disukai generasi z } \\
\text { yakni yang } \\
\text { dianggap keren. }\end{array}$ \\
\hline $\begin{array}{l}\text { Konsistensi dan } \\
\text { Loyalitas pada } \\
\text { Merek }\end{array}$ & $\begin{array}{l}\text { Pelayanan menjadi } \\
\text { hal utama agar } \\
\text { mereka berkenan } \\
\text { membeli sebuah } \\
\text { produk. Generasi x } \\
\text { tidak terlalu } \\
\text { memikirkan merek. }\end{array}$ & $\begin{array}{l}\text { Konsistensi dan } \\
\text { loyalitas terhadap } \\
\text { barang-barang } \\
\text { bermerk }\end{array}$ & $\begin{array}{l}\text { Produsen produk } \\
\text { bermerek dituntut } \\
\text { mereka untuk } \\
\text { memberikan lebih. } \\
\text { Loyalitas dari } \\
\text { produsen menjadi } \\
\text { tuntutan bagi } \\
\text { generasi z. }\end{array}$ \\
\hline $\begin{array}{l}\text { Cermat Atur } \\
\text { Uang saat } \\
\text { Belanja }\end{array}$ & $\begin{array}{l}\text { Kualitas menjadi } \\
\text { pertimbangan } \\
\text { utama, bukan } \\
\text { merek. }\end{array}$ & $\begin{array}{l}\text { Merek tetap yang } \\
\text { utama asalkan } \\
\text { terjangkau } \\
\text { harganya. }\end{array}$ & $\begin{array}{l}\text { Membeli karena } \\
\text { sesuai kebutuhan, } \\
\text { bukan keinginan } \\
\text { karena generasi ini } \\
\text { mengharapkan } \\
\text { lebih dari produk } \\
\text { yang dipakai. }\end{array}$ \\
\hline
\end{tabular}

Dalam jurnal yang ditulis oleh Nadiya (2017) mengatakan bahwa generasi y dalam memilih huniannya lebih menekankan pada rekomendasi kolega, baik teman maupun saudara dan mencari secara online karena menyukai internet. Selain itu, melihat perkembangan harga hunian, generasi y cenderung memilih menyewa rumah tapak atau membeli apartemen. Dengan membeli apartemen, generasi y memiliki keuntungan dalam hal pemilihan lokasi hunian yang sesuai dengan kebutuhan karena relatif berada di pusat kota dibandingkan rumah tapak yang sesuai dengan kemampuan finansialnya. Adapun menurut penelitian Ekananda (2019) terhadap generasi y dan z yang menjadi respondennya, keduanya masih mempertimbangkan memiliki rumah tapak dibandingkan apartemen. Namun, 
perbedaannya adalah generasi $\mathrm{z}$ yang menyukai perabot multifungsi. Sedangkan generasi y lebih memilih perabot satu fungsi. Hal tersebut menunjukkan adanya perbedaan preferensi antara generasi y dan z terhadap huniannya dalam beberapa aspek.

\section{METODE PENELITIAN}

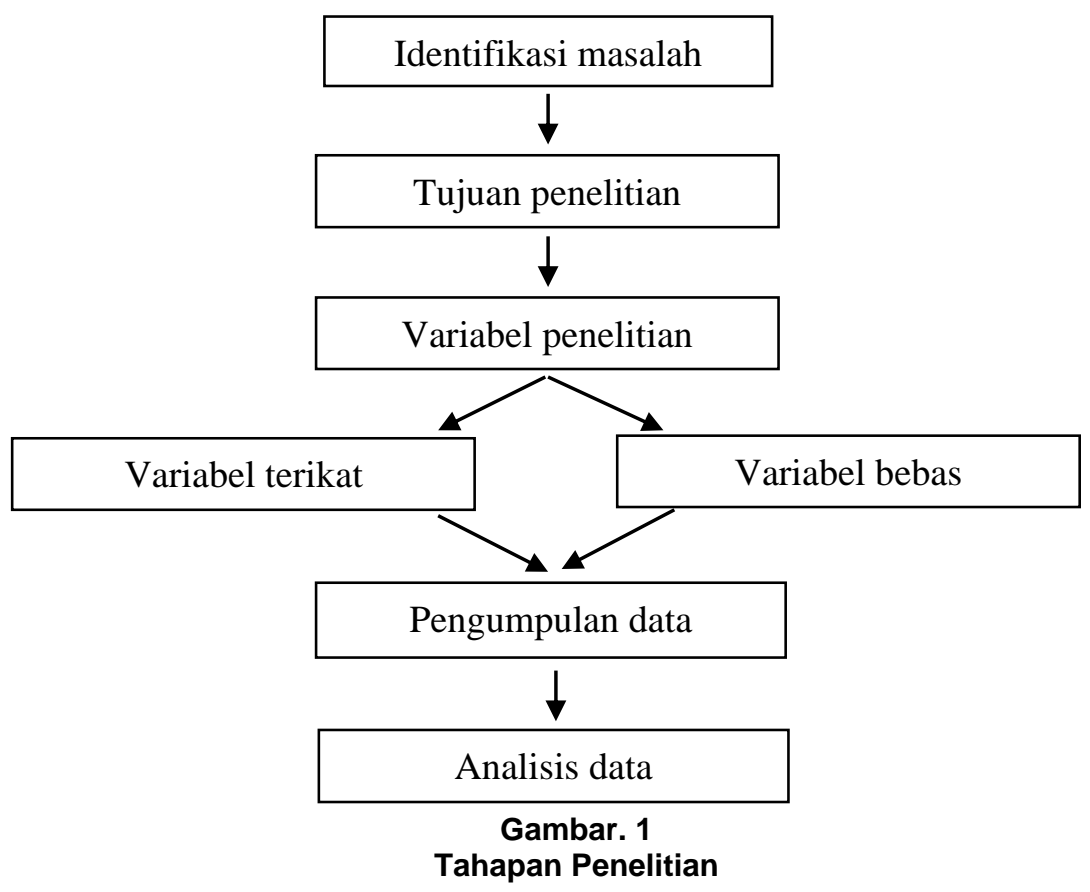

Penelitian ini merupakan penelitian kualitatif deskriptif. Metode pengumpulan data melalui data primer yang bersumber dari survei. Digunakanlah kuisioner yang berskala Likert dengan 4 pilihan yaitu "tidak setuju", "sangat tidak setuju", "setuju", dan "sangat setuju". Selain itu, dilakukan juga metode wawancara terhadap beberapa responden untuk menggali alasan dari pilihan jawaban mereka. Teknik analisis kualitatif digunakan dalam penelitian ini untuk hasil kuisioner, kemudian selanjutnya dilakukan terhadap hasil wawancara berdasarkan jawaban kuisioner responden tersebut.

Penelitian ini dilakukan di Kota Surabaya, Jawa Timur, Indonesia. Berikut ini merupakan gambar lokasi studi terhadap Indonesia (ditunjukkan dengan tanda bintang) : 


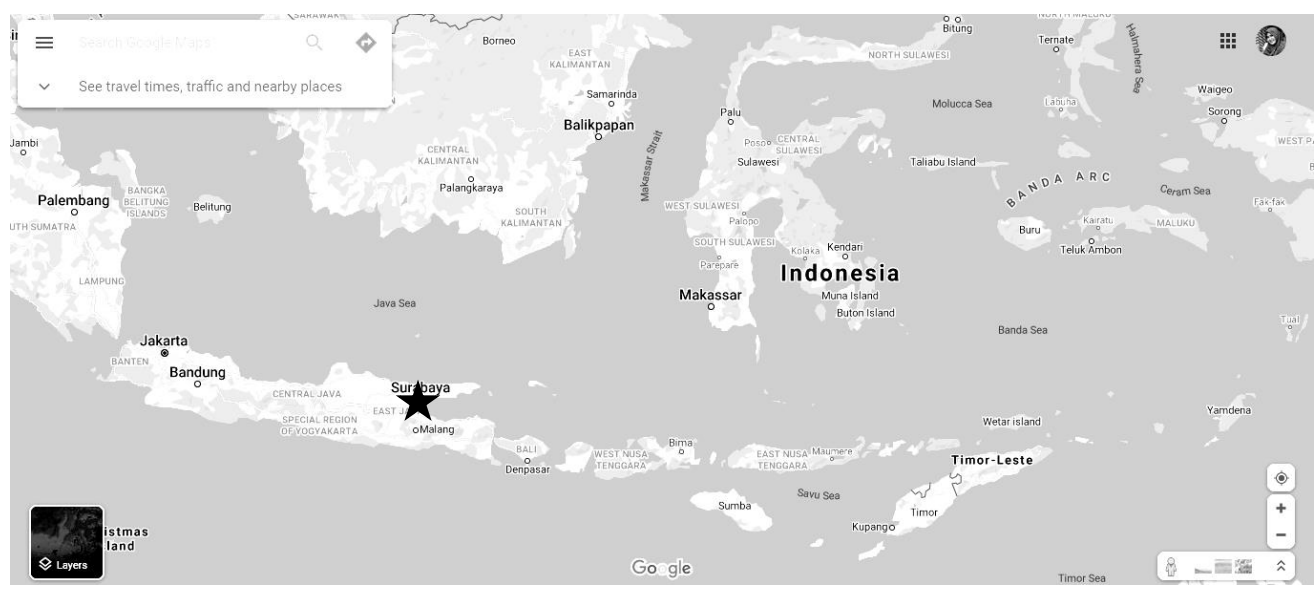

Gambar. 2

Posisi Surabaya dalam Peta

Sumber : Google Maps

Populasi dalam penelitian ini yakni generasi z dengan sampel berjumlah 300 orang. Teknik pengambilan sampel melalui Sampling Aksidental/Insidental yang langsung mencari responden secara 'kebetulan' atau tiba-tiba. Teknik ini termasuk dalam kategori non-probability sampling karena tidak akan ada kesamaan peluang maupun kesempatan bagi setiap unsur maupun anggota populasi untuk dipilih menjadi sampel (Sugiyono, 2011). Oleh karena itu, dibutuhkan kriteria responden yang akan dijadikan sampel agar hasil yang didapatkan nantinya bisa sesuai. Adapun kriteria penentuan sampel sebagai berikut :

1. Berusia antara $19-23$ tahun.

2. Saat ini berdomisili di Kota Surabaya.

Variabel yang diteliti terdiri dari "generasi z" sebagai variabel terikat, dan "jenis hunian berdasarkan perilaku belanja" sebagai variabel bebas. Berikut ini merupakan indikator untuk variabel terikat yang diteliti :

Tabel 3.

Variabel, Indikator, dan Definisi Operasional

\begin{tabular}{lll}
\multicolumn{1}{c}{ VARIABEL } & \multicolumn{1}{c}{ INDIKATOR } & \multicolumn{1}{c}{ DEFINISI OPERASIONAL } \\
\hline $\begin{array}{l}\text { Jenis Hunian } \\
\text { berdasarkan } \\
\text { Perilaku Belanja }\end{array}$ & $\begin{array}{l}\text { Cara mencari } \\
\text { produk yang ingin } \\
\text { dibeli }\end{array}$ & $\begin{array}{l}\text { Preferensi responden dalam mencari rumah } \\
\text { secara online atau berkeliling mencari rumah } \\
\text { secara langsung }\end{array}$ \\
\hline
\end{tabular}

PAWON: Jurnal Arsitektur, Nomor 02 Volume V, Juli-Desember Tahun 2021, ISSN 2597-7636 


\begin{tabular}{lll}
\hline VARIABEL & \multicolumn{1}{c}{ INDIKATOR } & \multicolumn{1}{c}{ DEFINISI OPERASIONAL } \\
\hline $\begin{array}{l}\text { Merek/ kredibilitas } \\
\text { pengembang } \\
\text { bergengsi }\end{array}$ & $\begin{array}{l}\text { Preferensi responden terhadap } \\
\text { merek/kredibilitas pengembang yang bergengsi }\end{array}$ \\
\cline { 2 - 3 } $\begin{array}{l}\text { Kepemilikan } \\
\text { hunian }\end{array}$ & $\begin{array}{l}\text { Preferensi responden terkait kepemilikan } \\
\text { hunian antara membeli atau sewa }\end{array}$ \\
\cline { 2 - 2 } $\begin{array}{l}\text { Jenis properti } \\
\text { hunian }\end{array}$ & $\begin{array}{l}\text { Preferensi responden untuk memilih jenis } \\
\text { huniannya antara Single/multi family, dan } \\
\text { Landed/highrise }\end{array}$ \\
& $\begin{array}{l}\text { Preferensi responden terhadap rumah yang } \\
\text { mengutamakan ruang bersama atau privasi tiap } \\
\text { individu. }\end{array}$ \\
\hline Privasi &
\end{tabular}

\section{HASIL DAN PEMBAHASAN}

Hasil pengumpulan data dari 300 responden dengan menggunakan kuesioner ini dirangkum lalu disajikan dalam bentuk deskripsi jawaban responden. Deskripsi jawaban merupakan hasil jawaban responden pada masing - masing indikator variabel penelitian. Berikut ini merupakan hasil deskripsi kriteria hunian menurut preferensi generasi $Z$ dalam aspek :

1. Cara mencari produk yang ingin dibeli

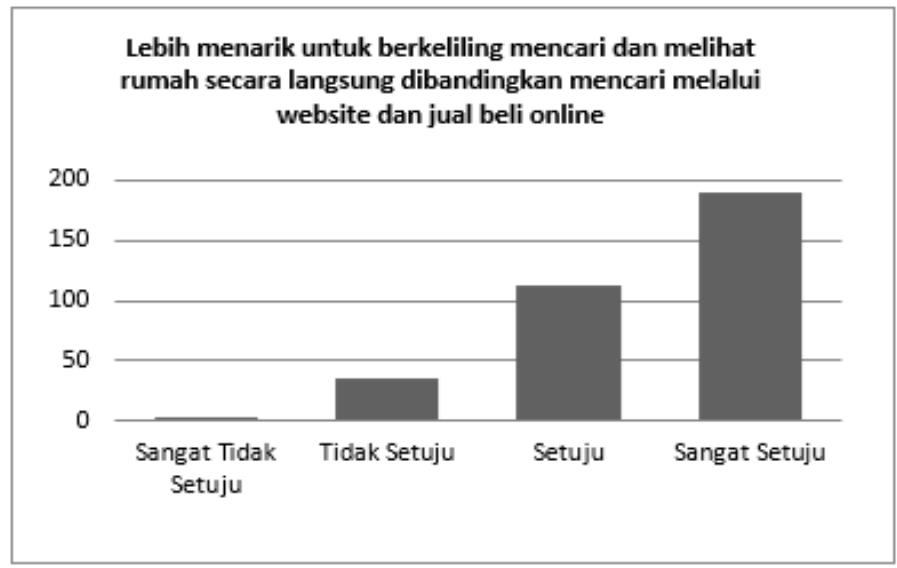

Gambar. 3

Hasil Kuisioner 1

Berdasarkan tabel perilaku belanja, generasi $z$ cenderung memanfaatkan smartphone untuk mencari produk yang ingin dibeli. Tapi, hal tersebut berbeda dengan hasil kuisioner responden penelitian ini dalam mencari produk hunian. Mayoritas merasa bahwa lebih menarik untuk berkeliling mencari dan melihat rumah secara langsung dibandingkan mencari melalui website dan jual beli online. Sebanyak 55,4\% responden 
sangat setuju dan $32,9 \%$ setuju. Sedangkan $10,5 \%$ tidak setuju serta $1,2 \%$ responden sangat tidak setuju.

Hal ini dapat disebabkan juga oleh karakteristik generasi z yang ingin mempunyai banyak pengalaman. Pengalaman nyata akan didapatkan lebih banyak dengan berkeliling langsung untuk melihat dan mencari rumah dibandingkan secara online. Meski dengan melakukannya membutuhkan waktu dan tenaga lebih, namun mereka akan mendapatkan hunian sesuai keinginan dan kebutuhannya. Berbeda dengan generasi y yang pada penelitian Nadiya (2017) yang memilih mencari hunian secara online karena mereka menyukai internet.

2. Merek/kredibilitas pengembang bergengsi

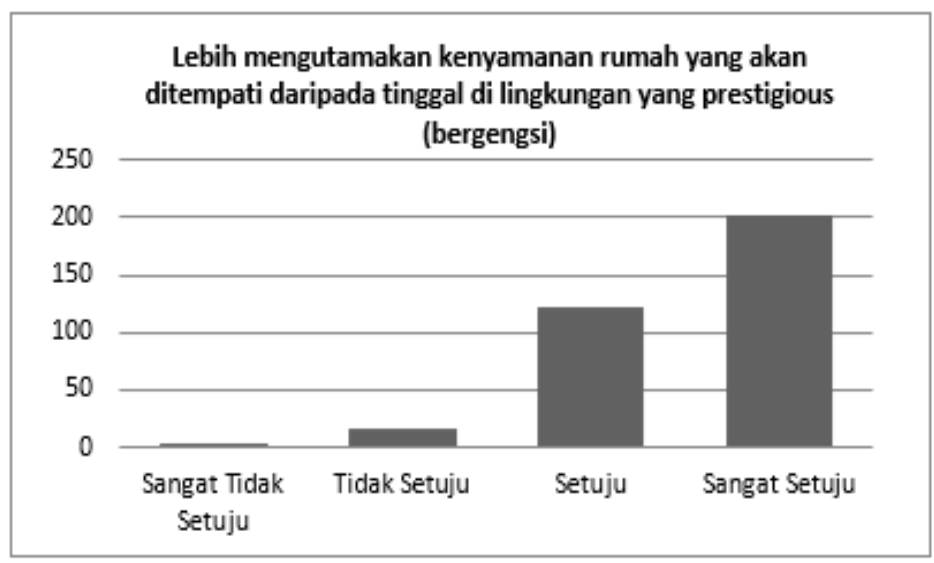

Gambar. 4

Hasil Kuisioner 2

Dalam hal ini, generasi $z$ berbeda pandangan dengan generasi y meski keduanya merupakan generasi milenial. Global Web Index merilis hasil surveinya tentang "Trends 18 - The Trends to Know for 2018". Dari survei itu, generasi z cenderung memilih produk yang menurut mereka keren tanpa peduli merek. Dalam hal ini, generasi z berbeda dengan generasi y yang mengutamakan merek (Muti'ah, 2012). Generasi z berbelanja dengan mengutamakan kebutuhan dibandingkan keinginan.

Ternyata hasil ini sesuai dengan jawaban responden yang lebih menomorsatukan kenyamanan dibanding gengsi huniannya. Sebanyak $58,9 \%$ responden sangat setuju dan $35,6 \%$ setuju terhadap pernyataan ini. Dari hasil wawancara, alasan responden yang tidak terlalu memikirkan tentang merek pengembang karena jika tinggal di lingkungan prestigious tentu akan ada biaya tambahan management estate untuk perawatan lingkungan. Mereka lebih mengutamakan kenyamanan meskipun tinggal di lingkungan yang biasa saja dan bukan merupakan hunian dari pengembang 
perumahan tertentu. Hanya 4,7\% yang tidak setuju dan 0,9\% yang sangat tidak setuju.

3. Kepemilikan hunian

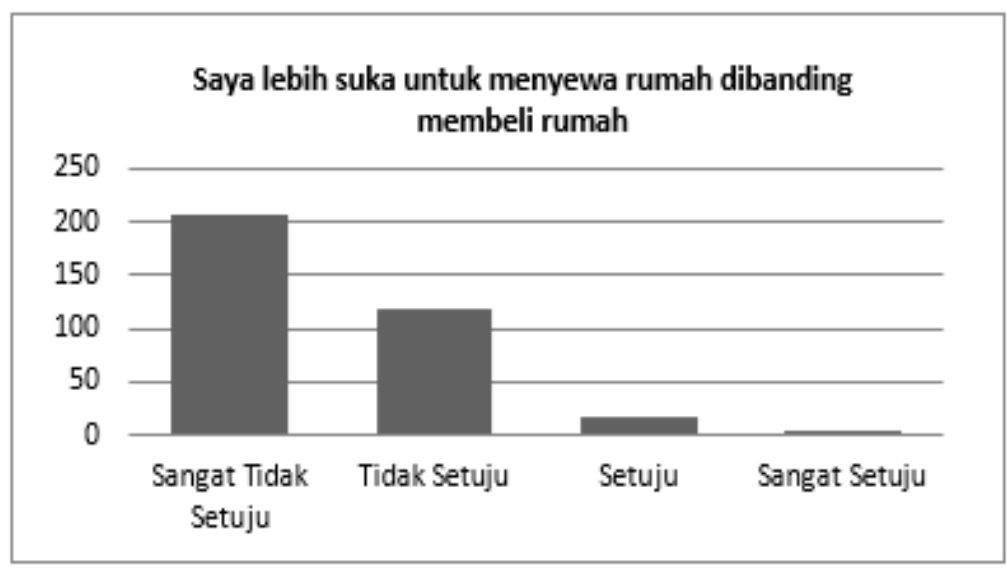

Gambar. 5

Hasil Kuisioner 3

Mayoritas responden sangat tidak setuju $(60,1 \%)$ dan tidak setuju $(34,4 \%)$. Hanya $4,7 \%$ responden setuju dan $0,9 \%$ sangat setuju untuk menyewa rumah dibanding membeli rumah. Alasannya yaitu mereka menginginkan jika sudah mengeluarkan uang untuk hunian maka mereka juga sebaiknya memiliki hunian tersebut. Jika menyewa, responden merasa telah 'membuang' uang untuk pemilik hunian yang mereka sewa. Selain itu, responden merasa kurang bebas untuk bisa melakukan sesuatu pada bangunan huniannya karena bangunan itu bukan miliknya.

Berbeda dengan survei yang dilakukan oleh CBRE Global Research terhadap generasi milenial di kawasan Asia-Pasifik, hasil survei menyebutkan sebanyak $23 \%$ responden yang lebih memilih untuk menyewa hunian dibandingkan membeli properti (11\%). Adapun $66 \%$ orang lainnya memilih jawaban lain. Menyewa hunian dianggap sebagai salah satu cara untuk bisa tinggal mandiri saat pendapatan belum bisa menjangkau untuk membeli rumah karena membeli rumah bukan target utama dari pengelolaan finansial mereka. Hasil survei CBRE ini sejalan dengan penelitian Nadiya (2017) terhadap generasi y bahwa menyewa rumah merupakan alternatif pilihan untuk memiliki rumah tapak yang terjangkau bagi mereka. 
4. Jenis Properti Hunian

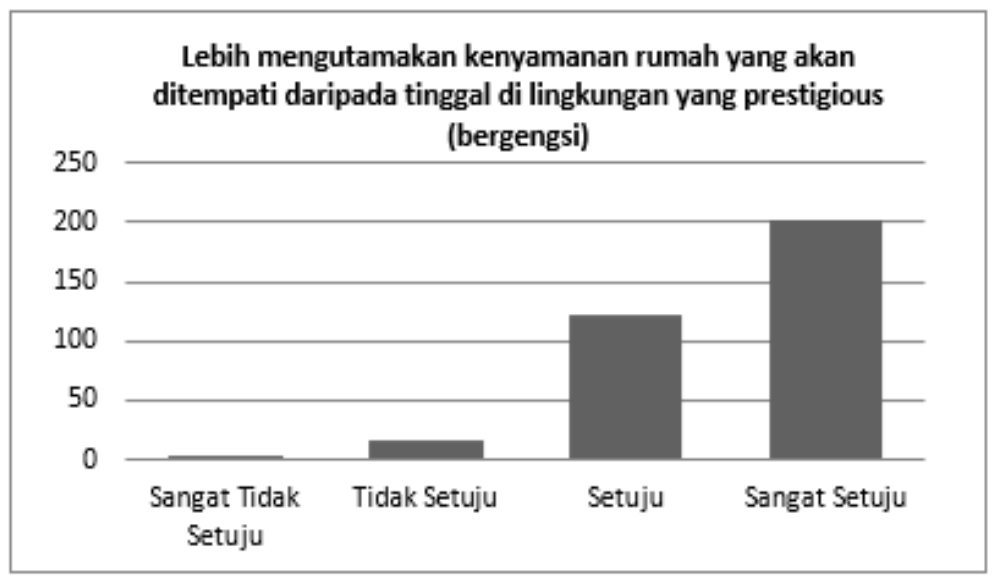

\section{Gambar. 6}

Hasil Kuisioner 4

Sebanyak 50,7\% responden tidak setuju serta $33,8 \%$ responden sangat tidak setuju untuk memilih tinggal di apartemen dibandingkan rumah tapak. Hanya $13,4 \%$ yang setuju dan $2 \%$ yang sangat setuju. Berdasarkan hasil wawancara, responden memilih rumah tapak karena mempertimbangkan tentang ketersediaan halaman rumah di setiap unitnya. Selain itu, responden merasa jika rumah tapak lebih memungkinkan terjadinya sosialisasi dengan tetangga. Sedangkan responden yang lebih menyukai apartemen beralasan karena pertimbangan kelengkapan fasilitas dan perawatan yang relatif lebih mudah dibanding merawat rumah tapak.

Kini pengembang perumahan mulai beralih ke penyediaan apartemen dibandingkan rumah tapak (Jacobus, 2010). Harga tanah yang semakin mahal membuat pengembang memilih pembangunan secara vertikal, selain juga akibat tuntutan jaman dan perubahan gaya hidup (Putri, 2016). Meski demikian, hasil penelitian Ekananda (2019) menyebutkan bahwa respondennya yang terdiri dari generasi y dan z masih lebih memilih rumah tapak. Sedangkan responden Nadiya (2017) yang merupakan generasi y memilih apartemen karena pertimbangan lokasi yang cenderung berada di pusat kota dibandingkan rumah tapak yang berada di pinggir kota. Kelengkapan fasilitas apartemen juga menjadi alasan mereka untuk lebih memilihnya. 
5. Privasi

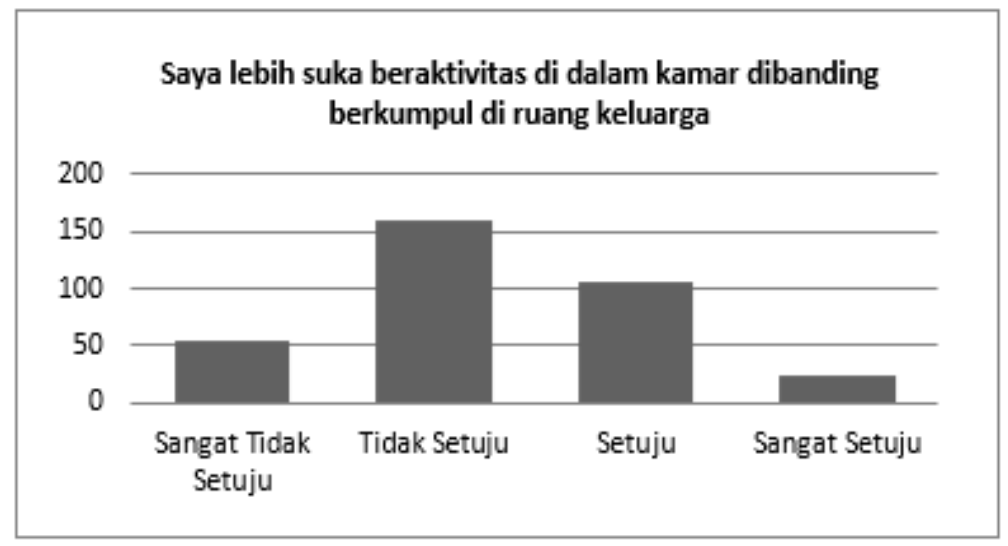

Gambar. 7

Hasil Kuisioner 5

Jawaban terbanyak responden ialah tidak setuju (46,6\%) dan $15 \%$ responden sangat tidak setuju terhadap pernyataan "Saya lebih suka beraktivitas di dalam kamar dibanding berkumpul di ruang keluarga". Mereka lebih memilih untuk berkumpul di ruang keluarga. Dari hasil wawancara, responden menganggap bahwa interaksi sosial dengan keluarga itu penting agar tidak menjadi pribadi yang individualis. Walaupun kamar sudah dilengkapi aneka fasilitas, namun responden merasa kurang nyaman karena harus sendiri.

Namun, sebanyak $30,6 \%$ responden setuju dan $7 \%$ sangat setuju dengan pernyataan tersebut. Meskipun demikian, hal ini menunjukkan bahwa responden cenderung tidak individualis serta menghargai nilai keluarga dan komunitas. Berbeda dengan karakter umum generasi y yang individualis seperti yang dijelaskan pada tabel 1 .

Dari kelima hasil pertanyaan kuisioner dalam penelitian ini, dapat dilihat bahwa ternyata ada perbedaan preferensi pilihan hunian generasi $z$ dengan generasi lainnya, khususnya generasi y. Meski keduanya termasuk generasi milenial, namun dibeberapa aspek terjadi preferensi yang berbeda. Hal ini sesuai dengan apa yang dikemukakan oleh Jansen (2011) bahwa 'common sense' tiap generasi berdampak pula pada preferensi umum mereka terhadap hunian. Berikut ini merupakan penjabaran preferensi pilihan jenis hunian responden berdasarkan indikator: 
1. Cara mencari produk yang ingin dibeli

Responden lebih memilih untuk berkeliling mencari rumah secara langsung dibandingkan mencari secara online. Melihat hal ini, estetika arsitektur dan fungsi produk hunian perlu diperhatikan agar dapat menarik minat konsumen generasi $z$ untuk membeli, terutama mengenai pengalaman rasa secara langsung dan nyata di lokasi hunian.

2. Merek/kredibilitas pengembang bergengsi

Responden mengutamakan kenyamanan rumah huniannya dibanding gengsi kredibilitas/merek pengembang perumahan. Oleh karenanya, produsen (developer) sebaiknya menyediakan hunian dengan mengutamakan desain yang nyaman, bukan hanya sekadar menjual nama perumahan dan merek pengembang perumahan.

3. Kepemilikan hunian

Responden memilih untuk membeli rumah daripada menyewa. Dari sini terlihat bahwa sebenarnya banyak responden masih lebih menginginkan memiliki rumah untuk menetap dibanding menyewa, sehingga perlu dipertimbangkan hunian yang memiliki harga jual yang sekiranya sesuai dengan pendapatan generasi $z$ nantinya.

4. Jenis properti hunian

Responden lebih memilih rumah tapak (landed) daripada apartemen (high rise). Melihat hal ini, perlu adanya penyesuaian terhadap jenis hunian berupa rumah tapak yang bisa mengakomodir keinginan konsumen, namun disesuaikan dengan kondisi harga tanah dan peralihan gaya hidup.

5. Privasi

Mayoritas responden memilih untuk berkumpul di ruang keluarga dibandingkan dengan beraktivitas dalam kamar. Berdasarkan hasil tersebut, tata ruang yang memungkinkan terjadinya interaksi sosial merupakan hal penting bagi sebuah hunian, seperti menyediakan ruang keluarga yang relatif luas dan terasa nyaman.

\section{KESIMPULAN}

Berdasarkan hasil studi ini, didapatkan kesimpulan bahwa perbedaan generasi mempengaruhi perilaku dan preferensi dalam memilih sebuah hunian. Meski generasi y dan z termasuk generasi milenial, namun ternyata ada beberapa karakteristik umum yang berbeda diantara keduanya, khususnya dalam perilaku belanja hunian. Hal ini dibuktikan dengan preferensi pilihan jenis hunian generasi $z$ yang menjadi responden dalam penelitian ini berdasarkan perilaku belanjanya, meliputi aspek cara mencari produk hunian yang ingin dibeli, merek/kredibilitas pengembang bergengsi, kepemilikan hunian, jenis properti hunian, dan privasi. 


\section{DAFTAR PUSTAKA}

Andersen, Bob \& Luke. 2006. Residential Real Estate Development : A Practical Guide For Beginners to Experts. Australia : Lulu Publisher

Ballantyne, A. 2002. What is Architecture. London : Routledge.

Brueggeman, William B., Jeffrey D. Fisher. 2001. Real Estate Finance and Investment. New York: The McGraw Hill Companies

Ekananda, A.N. \& Marcillia. S.M. (2019). Preferensi Atribut Fisik Hunian Generasi Y dan Z di Yogyakarta. SMART: Seminar on Architecture Research and Technology, 4(1), 327-335. Retrieved from https://smartfad.ukdw.ac.id/index.php/smart/article/view/119

Globe, Frank G. (1987). Psiokologi Humanistik Abraham Maslow. Yogyakarta: Kanisius.

Jacobus, C.J. (2010). Real Estate Principles : Eleventh Edition. Canada: Cengage Learning.

Jansen. (2011). The Measurement and Analysis of Housing Preference and Choice. Netherlands-London-New York: Springer.

Kasali, Rhenald. 2011. Membidik Pasar Indonesia: Segmentasi, Targeting, dan Positioning. Jakarta : PT Gramedia Pustaka Utama

Kotler, Philip. 1997. Manajemen Pemasaran. Surakarta: PT Pabelan Surakarta

Muti'ah, Farhatul. (2012). Studi Perilaku Konsumen dalam Pembelian Real Properti yang Pertama Kali di Surabaya. (Tesis Program Pascasarjana), Institut Teknologi Sepuluh Nopember, Surabaya.

Nadiya, Elzsa. (2017). Studi Preferensi Generasi Y dalam Memilih Hunian di Jakarta Barat. Jurnal Muara IImu Ekonomi dan Bisnis 1(1), 145-152, doi : 10.24912/jmieb.v1i1.417

Putri, Della Affesia. (2016). Pengambilan Keputusan Konsumen untuk Berinvestasi pada Apartemen dan Perumahan di Surabaya Timur. (Tesis Program Pascasarjana), Institut Teknologi Sepuluh Nopember, Surabaya.

Ramadhani, Viola Malta. (2018). Preferensi Berdasarkan Gaya Hidup Generasi Z sebagai Future Market Properti Hunian. (Tesis Program Pascasarjana), Institut Teknologi Sepuluh Nopember, Surabaya.

Rapoport, A. (2005). Culture, Architecture, dan Design. United States of America Locke Science Publishing Company, Inc.

Sudarman, Ari. (2004). Teori Ekonomi Mikro (Vol. 4). Yogyakarta: BPFE UGM. 
Sugiyono. 2011. Metode Penelitian Kuantitatif, Kualitatif, dan R\&D. Bandung: Alfabeta, cv.

Sunyoto, Danang. (2006). Dasar-dasar Manajemen Pemasaran. Yogyakarta: CAPS. 
